\title{
BMJ Open Prevalence of psychoactive substance use among acutely hospitalised patients in Oslo and Moscow: a cross-sectional, observational study
}

\author{
Danil Gamboa (10 , ${ }^{1,2}$ Benedicte Jørgenrud, ${ }^{1}$ Evgeny A Bryun, ${ }^{3,4}$ Vigdis Vindenes, ${ }^{1,5}$ \\ Evgenya A Koshkina, ${ }^{3}$ Aleksei V Nadezhdin, ${ }^{3,4}$ Saranda Kabashi, ${ }^{1,6}$ \\ Elena J Tetenova, ${ }^{3}$ Thomas Berg, ${ }^{1}$ Anna Armika Tussilago Nyman, ${ }^{1}$ \\ Alexey J Kolgashkin, ${ }^{3}$ Aleksei E Petukhov, ${ }^{3,7}$ Sergey N Perekhodov, ${ }^{8}$ \\ Elena N Davydova, ${ }^{8}$ Anners Lerdal, ${ }^{9,10}$ Gudmund Nordby, ${ }^{2}$ Stig Tore Bogstrand ${ }^{1,6}$
}

To cite: Gamboa D, Jørgenrud B, Bryun EA, et al. Prevalence of psychoactive substance use among acutely hospitalised patients in 0slo and Moscow: a cross-sectional, observational study. BMJ Open 2020;10:e032572. doi:10.1136/ bmjopen-2019-032572

- Prepublication history and additional material for this paper is available online. To view these files, please visit the journal online (http://dx.doi.org/10. 1136/bmjopen-2019-032572).

Received 28 June 2019 Revised 15 June 2020 Accepted 29 July 2020

Check for updates

(C) Author(s) (or their employer(s)) 2020. Re-use permitted under CC BY-NC. No commercial re-use. See rights and permissions. Published by BMJ.

For numbered affiliations see end of article.

Correspondence to

Dr Danil Gamboa;

danilgamboa@gmail.com

\section{ABSTRACT}

Objectives The use of psychoactive prescription medication is increasing in the general population. This is a cause for concern, particularly among the elderly, where physiological changes related to senescence increase the risk for adverse effects. While previous studies regarding psychoactive substance use have generally been population based, we sought to determine the frequency of such use among acutely hospitalised patients.

Setting Two emergency departments (EDs), one in 0slo and one in Moscow, admitting patients to Departments of Internal Medicine.

Participants 5583 patients aged $\geq 18$ years participated, distributed evenly between genders and study locations. Patients unable to give informed consent were excluded. The study sites did not admit patients with surgical conditions and/or injuries.

Primary and secondary outcomes The presence of psychoactive substances was determined through blood analysis using liquid chromatography-mass spectrometry. Secondary outcomes comprised demographic data (including age, gender, employment and marital status), degree of psychological distress, concurrent alcohol use, and self-reported alcohol, psychoactive drug and illicit substance use.

Results $32.3 \%$ in Oslo and $12 \%$ in Moscow were positive for one or more psychoactive medicinal drugs (benzodiazepines, z-hypnotics, opioids or barbiturates). In Oslo, medicinal drug use was associated with being aged 61 to 70 years (OR $2.40,95 \% \mathrm{Cl} 1.61$ to 3.58 ) compared with 18 to 40 years, and psychological distress (OR 2.61, $95 \% \mathrm{Cl} 2.06$ to 3.30). In Moscow, psychoactive medicinal drug use was also associated with psychological distress (OR 1.68, 95\% $\mathrm{Cl} 1.18$ to 2.39), and was less common among patients aged 41 to 60 years $(0 \mathrm{R} 0.62,95 \% \mathrm{Cl} 0.43$ to 0.88 ) than among patients aged 18 to 40 years.

Conclusion A significant proportion of admitted patients used one or more psychoactive medicinal drugs, in particular benzodiazepines (Oslo and Moscow) and opiates (0slo). We suggest formalised screening for inappropriate prescription drug use and increased adherence to clinical prescription guidelines.

\section{Strengths and limitations of this study}

- Blood sample analysis was used in addition to selfreporting to accurately assess the prevalence of psychoactive substance use.

- Large sample size divided across two sites, with an inclusion period lasting 1 year.

- Differences in laboratory methods, legislation and prescription practices for psychoactive substances between the selected sites limit comparability.

\section{INTRODUCTION}

\section{Background}

While the deleterious effects of harmful alcohol use and tobacco smoking are well known, several studies have also called attention to increasing rates of psychoactive prescription drug use in Western countries, especially among the elderly. ${ }^{1-3}$ These drugs include opioids, benzodiazepines and z-hypnotics. In addition to increased usage rates, there seems to be an apparent increase in the non-medical use and abuse of psychoactive medication, ${ }^{4}$ as well as inappropriate prescription practices and diversion from clinical guidelines. $^{2}$

Several studies have prospectively assessed the impact and usage rates of alcohol, psychoactive medication and illicit substances in the ED. ${ }^{5-8}$ Alcohol-related presentations to the ED have been quantified both through the use of questionnaires, and classification through the International Classification of Diseases, Tenth Revision (ICD-10). However, patients may under-report alcohol consumption when presented with a questionnaire, and self-reporting may be limited by recall bias. ${ }^{9}$ Potentially harmful, but not clinically apparent, alcohol-related presentations may 
also remain undetected by health professionals and thus misclassified. These limitations may attenuate the accuracy of prevalence data in such studies. A study published in $2011^{10}$ used blood sample analysis using highly selective methods to assess the prevalence of psychoactive substances among patients acutely admitted due to injury-this provided accurate and reliable prevalence data. However, blood sample analysis has not been used to assess the prevalence of psychoactive substances among patients acutely admitted to Departments of Internal Medicine.

Patients admitted to Departments of Internal Medicine are likely to be older than the general population. ${ }^{11}$ The elderly are more vulnerable to any potential adverse effects from psychoactive medication use due to age-related changes in the pharmacodynamic and pharmacokinetic properties of various drugs. ${ }^{12}{ }^{13}$ Changes in physiology and body composition related to ageing increases the susceptibility to adverse effects from alcohol consumption, ${ }^{14}$ and the concurrent use of psychoactive drugs and alcohol also exacerbates the respective adverse effects of each substance. Drowsiness and reduced postural stability are common effects of psychoactive drugs, and these are enhanced by alcohol consumption. Consequently, both drug-drug and drug-alcohol interactions may cause clinically significant adverse reactions in the elderly, such as falls, injury and infections. ${ }^{1}$ These events may be precipitated even by low-to-moderate doses of the substances mentioned. Polypharmacy-the concurrent use of multiple medications-increases in frequency with age, with rates ranging from $12 \%$ to $35 \%$ among the elderly in Western countries. ${ }^{15}$ This may contribute to the additive risk for adverse drug-drug interactions. Considering the high frequency of use among older adults, knowledge regarding the prevalence of these substances among acutely hospitalised patients may be of clinical significance. Psychoactive medication, specifically benzodiazepines and z-hypnotics, is also often used to treat psychological distress and sleep disorders, which are common among the elderly. ${ }^{16}$ Contrary to alcohol, which is usually independently procured, and where ingestion is user-initiated, the distribution of psychoactive medication is generally mediated by health professionals. In light of increased rates of non-medical use and abuse of these drugs ${ }^{4}$ the presence of reliable and accurate prevalence data may mediate prudence regarding prescription practices, and lead to more critical appraisals of when these drugs are necessary or should be discontinued.

\section{Study aims}

In this study, we sought to assess the prevalence of psychoactive substances among patients acutely hospitalised to Departments of Internal Medicine.

Specifically, we wished to:

1. Measure the rate of psychoactive substance use through the use of blood sampling and highly selective analytical methods.
2. Investigate patient characteristics when a psychoactive substance is detected; namely age, gender, employment status, marital status, degree of psychological distress and self-reported alcohol consumption.

3. Investigate the concurrent rate of alcohol and illicit drug use when psychoactive substances are detected.

This study is part of a larger collaborative project between Oslo University Hospital and the Moscow Research Center on Addiction.

\section{METHODS}

Study design, setting and participants

Design and site selection

We have employed an observational, cross-sectional approach. We chose two study sites-

Lovisenberg Diaconal Hospital (LDS) in Oslo, Norway (site 1) and Hospital No. 68 in Moscow, Russia (site 2). Both sites are medium-sized urban hospitals. The mean life expectancy in Norway is 84.2 years for women and 80.6 years for men, ${ }^{17}$ which is significantly higher than in Russia, where the mean life expectancy is 72.1 years. ${ }^{18}$ However, due to socioeconomic disparities within the various districts in Oslo, the life expectancy in several populations belonging to the catchment area for LDS approaches that in Russia, ranging from 72 to 76 years for men and 79 to 81 years for women,. ${ }^{19}$ Due to differences in laboratory techniques, prescription practices as well as guidelines and legislation for psychoactive drug use in each nation, results for each site will be presented separately.

\section{Inclusion and exclusion criteria}

In Oslo, patients were generally either recruited by emergency department (ED) nurses while awaiting ward transfer or examinations such as radiographic imaging, or shortly after arrival to their respective ward, while in Moscow, patients were recruited on arrival to the ward by physicians serving as dedicated study and recruitment coordinators. The EDs in Oslo and Moscow were both located at the Department of Internal Medicine, and therefore did not admit patients with injuries or surgical conditions. Patients were transferred to an appropriate ward after an initial evaluation, which in Oslo was General Internal Medicine, Infectious Diseases, Cardiology, Pulmonary Medicine, Cerebrovascular and Geriatric conditions, Haematology or Gastroenterology, and in Moscow patients were transferred to General Internal Medicine, Cardiology, Pulmonary Medicine or Neurology. Only patients aged 18 years and above and able to give informed consent were included. Patients unable to consent on admission due to reversible or transient causes (such as intoxication or severe illness) were approached at a later time by dedicated research assistants, and were offered to participate when they were able to consent. The inclusion period lasted from November 2016 to December 2017, and patients were included at all hours of the day, to account for any seasonal or diurnal 


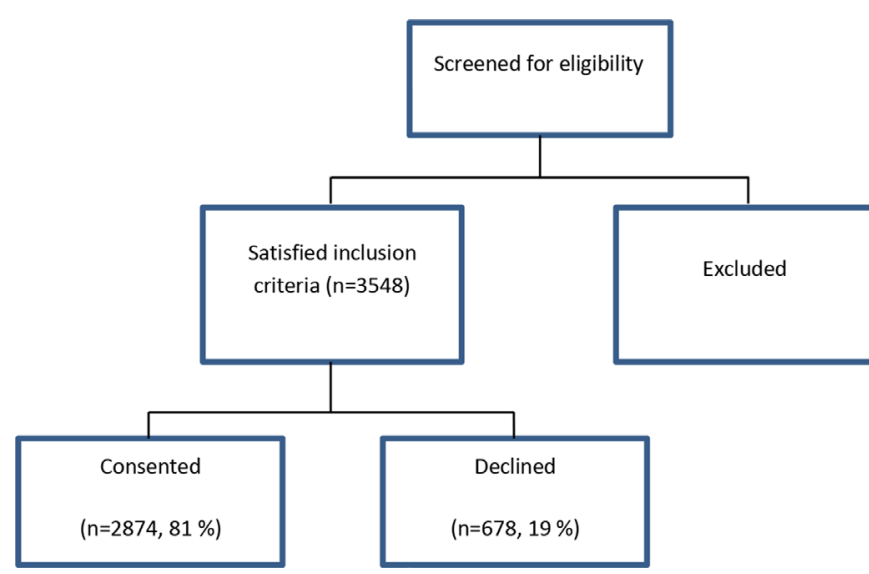

Figure 1 Flow diagram for patient recruitment in Oslo. All admitted patients were screened for eligibility. Patients permanently unable to give an informed consent, as well as patients electively transferred from other hospitals, were excluded.

variations. We employed the following exclusion criteria: (1) permanently unable to give an informed consent; (2) elective transfer from other hospitals; and (3) limited or no ability to read or write the national language, either Russian or Norwegian, as translated copies of both the consent form and accompanying questionnaire were unavailable. Figures 1 and 2 detail the flow of patient recruitment.

\section{Patient and public involvement}

There was no patient or public involvement in the design and implementation of this study. In addition to disseminating results to clinicians and policy makers, we intend to inform and involve patient interest organisations in the field of substance use disorders.

\section{Variables}

Study design, variables and analytical methods were jointly developed by the research teams at both study sites to maintain consistency in data collection and collation.

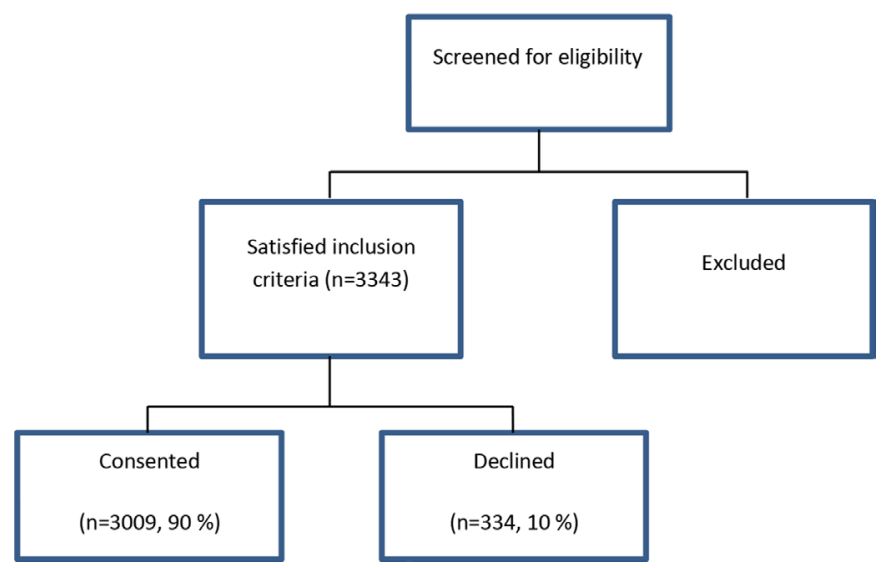

Figure 2 Flow diagram for patient recruitment in Moscow. All admitted patients were screened for eligibility. Patients permanently unable to give an informed consent, as well as patients electively transferred from other hospitals, were excluded.
The study sites were also visited by the respective study researchers to ensure methodological continuity.

\section{Blood analysis}

Whole blood was drawn from every study participant and secured in $5 \mathrm{~mL}$ BD Vacutainer blood collection glass tubes (BD Vacutainer Systems, Franklin Lakes, New Jersey, USA). The blood samples were stored at $4^{\circ} \mathrm{C}$ for a maximum of 7 days before analysis. In Oslo, the samples were analysed at the Division of Laboratory Medicine, Section of Drug Abuse Research, Oslo University Hospital. We prepared the samples by 96 -well supported liquid extraction, which were then analysed by liquid chromatography-tandem mass spectrometry (LC-MS/ MS). This is the same sample preparation and LC-MS/ MS method used by Kristoffersen et al..$^{20}$ Stable isotopelabelled internal standards were used for all compounds. Two multiple reaction monitor (MRM) transitions were used for each compound and each internal standard. The chosen detection limits (cut-off limit) were based on validation data and signal/noise $(\mathrm{S} / \mathrm{N})$ ratio of the quantifier MRM transition $(\mathrm{S} / \mathrm{N} \geq 10)$. For tetrahydrocannabinol (THC), $\mathrm{S} / \mathrm{N} \geq 3$ was used. The Russian samples were analysed at the Moscow Research Center for Addiction. Blood samples were prepared by protein precipitation and analysed by ultra-high performance LC-MS/MS. Two MRM transitions were used for each compound. The cutoff level for each analyte was defined as a signal corresponding to $\mathrm{S} / \mathrm{N}=1000$ for the quantifier MRM transition. We have provided additional methodological details and validation data for the Oslo site in online supplemental table 1.

Any sample in which the patient was administered a psychoactive medicinal drug by healthcare personnel prior to blood sampling was omitted from the resultsspecifically, morphine and diazepam at the Oslo site, and diazepam, phenazepam and tramadol at the Moscow site. In order to distinguish medicinal morphine use from heroin use, a morphine/codeine ratio cut-off value of $>1$ was used. ${ }^{21}$ Similarly, concentration ratios of methamphetamine to amphetamine were used to distinguish methamphetamine use from various mixtures of the two stimulants. $^{22}$

\section{Questionnaire}

Upon enrolment, every patient filled out a questionnaire containing demographic data: age ranges (18 to 40,41 to 60,61 to 70 and $\geq 71$ years), gender (male/female), marital status (single, married or widowed) and employment status (employed, retired, unemployed or student). Psychological distress was measured using the Symptom Checklist 5 (SCL-5), a short-form screening tool which performs almost as well as the full version. ${ }^{23}$ A value above two points indicates psychological distress. Self-reported alcohol use was measured through the Alcohol Use Disorder Identification Test-4 (AUDIT-4), which has been validated as a simple yet effective screening tool for identifying alcohol use disorders. ${ }^{2425}$ A value of 7 points or more 
for men and 5 points or more for women indicates at-risk alcohol consumption patterns. Both questionnaires have been validated for use in their respective nations. ${ }^{26-28}$ The questionnaires were filled out by the patients themselves, with occasional aid from emergency room (ER) nurses at the Oslo site if questions arose. The ER nurses were also instructed beforehand by the study coordinator, and a data collection pilot preceded the inclusion period. We also included self-reported use of benzodiazepines and/ or barbiturates (termed 'sedatives'), z-hypnotics (termed 'sleeping medication'), opioids (termed 'painkillers') and illicit drugs (termed 'narcotic substances'). All drug groups had example trade or colloquial names to improve question comprehension.

Questionnaires were manually entered, controlled and later transferred to the electronic project database.

\section{Psychoactive substances}

Our primary outcome was the presence of a psychoactive substance, determined through analytical cut-off values (tables 1 and 2). Psychoactive medicinal drugs were defined as opioids, benzodiazepines, z-hypnotics or barbiturates. The specific drugs were selected based on prescription practices among primary care and hospital

Table 1 Prevalence of illicit substances and psychoactive medication among all admitted patients in Oslo

\begin{tabular}{|c|c|c|c|c|}
\hline & Cut-off (nmol/L) & Mean concentration (nmol/L) & Number of positive samples & Per cent \\
\hline Illicit & & & 167 & 6.4 \\
\hline Amphetamines & & & 55 & 2.1 \\
\hline Amphetamine & 200 & 1696 & 21 & 0.8 \\
\hline Methamphetamine & 200 & 1859 & 45 & 1.7 \\
\hline Cocaine* & & & 30 & 1.2 \\
\hline Benzoylecgonine & 10 & 1587 & 22 & 0.8 \\
\hline Cocaine & 0.6 & 242 & 26 & 1.0 \\
\hline Heroin & $M / C>1$ & & 24 & 0.9 \\
\hline MDMA ecstasy & 200 & 1063 & 4 & 0.2 \\
\hline $\mathrm{THC}$ & 2 & 15 & 97 & 3.7 \\
\hline Medicinal & & & 843 & 32.3 \\
\hline Alprazolam & 1 & 40 & 19 & 0.7 \\
\hline Buprenorphine & 4 & 10 & 7 & 0.3 \\
\hline Clonazepam & 0.4 & 127 & 98 & 3.8 \\
\hline Codeine & 3 & 167 & 181 & 6.9 \\
\hline Diazepam & 20 & 402 & 251 & 9.6 \\
\hline Flunitrazepam & 0.5 & 5 & 6 & 0.2 \\
\hline Methadone & 20 & 1142 & 46 & 1.8 \\
\hline Morphine & 3 & 90 & 107 & 4.1 \\
\hline Nitrazepam & 5 & 139 & 93 & 3.6 \\
\hline Oxycodone & 5 & 193 & 91 & 3.5 \\
\hline Oxazepam & 50 & 822 & 215 & 8.2 \\
\hline Tramadol & 20 & 743 & 121 & 4.6 \\
\hline Zolpidem & 70 & 406 & 32 & 1.2 \\
\hline Zopiclone & 20 & 57 & 139 & 5.3 \\
\hline Z-hypnotics & & & 171 & 6.6 \\
\hline Benzodiazepines & & & 482 & 18.5 \\
\hline Opioids & & & 507 & 19.5 \\
\hline Alcohol† & & & 94 & 3.6 \\
\hline Medicinal and/or illicit & & & 900 & 34.5 \\
\hline
\end{tabular}

${ }^{*}$ Cocaine-positive is defined as a sample positive for either cocaine or benzoylecgonine. Because the recovery of benzoylecgonine is very low using SLE extraction, a patient may be positive for cocaine, but negative for benzoylecgonine.

†Alcohol-positive is defined as blood alcohol content $>0.1 \mathrm{~g} / \mathrm{kg}$.

M/C, morphine/codeine ratio ; MDMA, 3,4-Methylenedioxymethamphetamine; SLE, supported liquid extraction; THC, tetrahydrocannabinol. 
Table 2 Prevalence of illicit substances and psychoactive medication among all admitted patients in Moscow

\begin{tabular}{|c|c|c|c|}
\hline & $\begin{array}{l}\mathrm{S} / \mathrm{N} \\
\text { ratio* }\end{array}$ & $\begin{array}{l}\text { Number } \\
\text { of } \\
\text { positive } \\
\text { samples }\end{array}$ & Percent $†$ \\
\hline Illicit & & 43 & 1.4 \\
\hline Amphetamines & 1000 & 5 & 0.2 \\
\hline Amphetamine & & 4 & 0.14 \\
\hline Methamphetamine & & 1 & 0.03 \\
\hline Cocaine & & 1 & 0.03 \\
\hline Benzoylecgonine & & 1 & 0.03 \\
\hline Heroin & & 2 & 0.07 \\
\hline MDMA ecstasy & & 2 & 0.07 \\
\hline $\mathrm{THC}$ & & 32 & 1.1 \\
\hline Alpha PVP & & 3 & 0.10 \\
\hline Methadone & & 6 & 0.20 \\
\hline Medicinal§ & & 361 & 12.0 \\
\hline Clonazepam & & 1 & 0.03 \\
\hline Codeine & & 1 & 0.03 \\
\hline Dextromethorphan & & 1 & 0.03 \\
\hline Diazepam & & 61 & 2.0 \\
\hline Phenazepam & & 240 & 8.0 \\
\hline Phenobarbital & & 68 & 2.3 \\
\hline Pregabalin & & 9 & 0.3 \\
\hline Tramadol & & 13 & 0.4 \\
\hline Barbiturates & & 68 & 2.3 \\
\hline Benzodiazepines & & 291 & 9.7 \\
\hline Opioids & & 28 & 0.9 \\
\hline Alcohol & & 30 & 1.0 \\
\hline Medicinal and/or illicit & & 393 & 13.1 \\
\hline
\end{tabular}

*In Moscow, the detection limit was based on a S/N ratio above 1000, which applies for all substances listed. In Oslo, absolute lower detection limits were used.

†In instances of substances being detected in a very small number of samples, percentages are presented with 2 decimal points. $\ddagger$ Cocaine-positive is defined as a sample positive for either cocaine or benzoylecgonine. Because the recovery of benzoylecgonine is very low using SLE extraction, a patient may be positive for cocaine, but negative for benzoylecgonine §In Moscow, several other substances were analysed in addition to those listed in table 2-these were omitted due to lack of positive samples.

ПAlcohol-positive is defined as blood alcohol content $>0.1 \mathrm{~g} / \mathrm{kg}$. alpha PVP, alpha-pyrrolidinovalerophenone; MDMA, 3,4-Methylen edioxymethamphetamine; SLE, supported liquid extraction; S/N, signal/noise; THC, tetrahydrocannabinol.

physicians, as well as hospital usage rates. Due to differences in prescription practices, certain substances were omitted at the Moscow site, and vice versa for the Oslo site. Specifically, the use of z-hypnotics in Russia is very uncommon, and phenazepam, a commonly prescribed benzodiazepine in Russia, is not marketed in Norway. ${ }^{29}$
Barbiturates are also commonly used as a sedative in Russia, but this use is uncommon in Norway.

The presence of alcohol was determined through direct analysis of blood alcohol content. Based on population studies, the most common illicit drugs and their metabolites were analysed-these comprise amphetamines, methamphetamines, cocaine, MDMA (3,4-Methylenediox ymethamphetamine)/ecstasy, heroin and THC. So-called 'new psychoactive substances' were not analysed-the rapid introduction of new compounds poses significant analytical challenges, and selecting which substance to analyse is complicated by limited knowledge regarding their availability in the general population. ${ }^{30}$ Polyuse was defined as the presence of two or more psychoactive substances (prescription medication and/or illicit drugs) in any given blood sample.

\section{Statistical analysis}

We analysed the data using IBM SPSS 25.0 (Armonk, New York, USA). The prevalence of various psychoactive substances is shown through descriptive tables. We employed bivariate cross tables to analyse associations between the presence of a psychoactive substance and sample characteristics. $\chi^{2}$ statistics with ORs were used to assess statistical significance. Our primary dependent variable was the presence of any psychoactive medicinal substance. Our covariates were age ranges, marital status, employment status, positive blood alcohol content, presence of illicit drugs, polyuse, presence of psychological distress and self-reported alcohol use. We performed logistic regression analyses to test the association between our dependent values, which were medicinal drug use, illicit drug use and polyuse, and independent covariates, which were age, gender, SCL-5 values, marital status, employment status and AUDIT-4 zones. Our reference categories for each variable were age 18 to 40 years, male gender, SCL-5 score $\leq 2$, married, active in the workforce and an AUDIT score of 0 to 3. The level of significance was set at $\mathrm{p}<0.05$. Continuous data are presented as means, with $95 \%$ CIs.

\section{RESULTS \\ Participants}

A total of 2874 patients in the Oslo site and 3009 patients in the Moscow site were included, with a participation rate of $81 \%$ and $90 \%$, respectively- $47.6 \%$ were women in Oslo and 52.9\% were women in Moscow. Distribution across age ranges was similar at both sites (tables 3 and 4 ).

\section{Prevalence data and sample characteristics \\ Prevalence data}

Tables 1 and 2 depict the main findings in our study, showing prevalence data for all psychoactive substances analysed and their analytical cut-off values. In Oslo, psychoactive medicinal drugs were detected in $32.3 \%$ of analysed samples. The most common drug class detected was opioids (19.5\%), followed by benzodiazepines 
Open access

Table 3 Medicinal drug use ${ }^{*}$ and demographic data, SCL-5, concurrent illicit drug use and AUDIT-4 in Oslo

\begin{tabular}{|c|c|c|c|c|}
\hline & Medicinal no N (\%) & Medicinal yes N (\%) & Total N (\%) & P value $\left(\chi^{2}\right)$ \\
\hline Gender & & & & $\mathrm{p}=0.66$ \\
\hline Female & $832(48)$ & $388(47)$ & $1220(48)$ & \\
\hline Male & 907 (52) & $439(53)$ & 1346 (52) & \\
\hline Total & 1739 & 827 & 2566 & \\
\hline Age (years) & & & & $p<0.001$ \\
\hline 18 to 40 & $593(34)$ & $113(14)$ & $706(28)$ & \\
\hline 41 to 60 & $424(25)$ & $214(26)$ & $638(25)$ & \\
\hline 61 to 70 & $317(18)$ & $222(27)$ & $539(21)$ & \\
\hline$\geq 71$ & $398(23)$ & $276(34)$ & $674(26)$ & \\
\hline Total & 1732 & 825 & 2557 & \\
\hline Marital status & & & & $p<0.001$ \\
\hline Married/co-habitant & $814(48)$ & $266(34)$ & $1080(43)$ & \\
\hline Divorced & $242(14)$ & $176(22)$ & $418(17)$ & \\
\hline Widowed & $124(7)$ & $99(13)$ & $223(9)$ & \\
\hline Single & $525(31)$ & $245(31)$ & $770(31)$ & \\
\hline Total & 1705 & 786 & 2491 & \\
\hline Employment & & & & $p<0.001$ \\
\hline Active & $985(58)$ & $188(24)$ & $1173(47)$ & \\
\hline Retired & $548(33)$ & $393(50)$ & $941(38)$ & \\
\hline Non-active & $154(9)$ & $211(27)$ & $365(15)$ & \\
\hline Total & 1687 & 792 & 2479 & \\
\hline SCL-5 & & & & $\mathrm{p}<0.001$ \\
\hline$\leq 2$ & $1383(84)$ & $460(62)$ & $1843(77)$ & \\
\hline$>2$ & $263(16)$ & $279(38)$ & $542(23)$ & \\
\hline Total & 1646 & 739 & 2367 & \\
\hline Illicit drugs in blood & & & & $\mathrm{p}<0.001$ \\
\hline No & 1707 (97) & $733(87)$ & $2440(94)$ & \\
\hline Yes & $57(3)$ & $110(13)$ & $167(6)$ & \\
\hline Total & 1764 & 843 & 2607 & \\
\hline AUDIT-4 & & & & $\mathrm{p}<0.001$ \\
\hline 0 to 3 & $901(54)$ & $506(64)$ & $1407(57)$ & \\
\hline 4 to 6 & $537(32)$ & $147(19)$ & $684(28)$ & \\
\hline 7 to 8 & $126(8)$ & $52(7)$ & $178(7)$ & \\
\hline 9 to 16 & $107(6)$ & $85(11)$ & $192(8)$ & \\
\hline Total & 1671 & 790 & 2461 & \\
\hline Blood alcohol content & & & & $\mathrm{p}=0.03$ \\
\hline$<0.1 \%$ & $1710(97)$ & $803(95)$ & $2513(96)$ & \\
\hline$\geq 0.1 \%$ & $54(3)$ & $40(5)$ & $94(4)$ & \\
\hline Total & 1764 & 843 & 2607 & \\
\hline Polyuse & & & & $p<0.001$ \\
\hline$<2$ & $1760(100)$ & $462(55)$ & $2222(85)$ & \\
\hline$\geq 2$ & $4(0.2)$ & $381(45)$ & $385(15)$ & \\
\hline Total & 1764 & 843 & 2607 & \\
\hline
\end{tabular}

*Medicinal drugs are defined as the presence of benzodiazepines, z-hypnotics or opioids.

AUDIT-4, Alcohol Use Disorder Identification Test-4; SCL-5, Symptom Checklist 5 . 
Table 4 Medicinal drug use* and demographic data, SCL-5, concurrent illicit drug use and AUDIT-4 in Moscow

\begin{tabular}{|c|c|c|c|c|}
\hline & Medicinal no N (\%) & Medicinal yes N (\%) & Total N (\%) & P value $\left(\chi^{2}\right)$ \\
\hline Gender & & & & $\mathrm{p}=0.18$ \\
\hline Female & $1412(53)$ & $179(50)$ & 1591 (53) & \\
\hline Total & 2648 & 361 & 3009 & \\
\hline Age (years) & & & & $p=0.14$ \\
\hline 41 to 60 & $821(31)$ & $103(29)$ & 924 (31) & \\
\hline 61 to 70 & $663(25)$ & $79(22)$ & $742(25)$ & \\
\hline$\geq 71$ & $719(27)$ & $102(28)$ & $815(27)$ & \\
\hline Total & 2654 & 361 & 3009 & \\
\hline Marital status & & & & $p=0.03$ \\
\hline Widowed & $704(27)$ & $106(29)$ & $810(27)$ & \\
\hline Single & $303(11)$ & $41(11)$ & $344(11)$ & \\
\hline Total & 2648 & 361 & 3009 & \\
\hline Employment & & & & $p<0.001$ \\
\hline Active & $816(31)$ & $81(22)$ & $897(30)$ & \\
\hline Retired & $401(15)$ & $90(25)$ & $491(16)$ & \\
\hline Non-active & $1430(54)$ & $190(53)$ & $1620(54)$ & \\
\hline Total & 2647 & 361 & 3008 & \\
\hline SCL-5 & & & & $\mathrm{p}<0.001$ \\
\hline Total & 2648 & 361 & 3009 & \\
\hline AUDIT-4 & & & & $\mathrm{p}<0.001$ \\
\hline 0 to 3 & $1986(75)$ & $228(63)$ & $2214(74)$ & \\
\hline 4 to 6 & $222(8)$ & $16(4)$ & $238(8)$ & \\
\hline 7 to 8 & $110(4)$ & $13(4)$ & $123(4)$ & \\
\hline \multirow[t]{2}{*}{9 to 16} & $326(12)$ & $103(29)$ & $429(14)$ & \\
\hline & 2644 & 360 & 3004 & \\
\hline Blood alcohol content & & & & $p=0.51$ \\
\hline$<0.1 \%$ & $2626(99)$ & $353(98)$ & $2979(99)$ & \\
\hline$\geq 0.1 \%$ & $22(1)$ & $8(2)$ & $30(1)$ & \\
\hline Total & 2648 & 361 & 3009 & \\
\hline Polyuse & & & & $\mathrm{p}<0.001$ \\
\hline$<2$ & $2642(100)$ & $319(88)$ & $2961(98)$ & \\
\hline$\geq 2$ & $6(0)$ & $42(12)$ & $48(2)$ & \\
\hline Total & 2648 & 361 & 3009 & \\
\hline
\end{tabular}

*Medicinal drugs are defined as the presence of benzodiazepines, barbiturates or opioids. AUDIT-4, Alcohol Use Disorder Identification Test-4; SCL-5, Symptom Checklist 5. 
(18.5\%). Z-hypnotics were found in $6.6 \%$ of samples. In the Moscow site, psychoactive medicinal drugs were detected in $12 \%$ of samples-benzodiazepines were the most frequently detected drug class $(9.7 \%)$. The rates for other drug classes were low, with opioids found in $0.9 \%$.

In Oslo, illicit drugs were detected in $6.4 \%$ of all samples, with THC (3.7\%) being the most common. In the Moscow site, the total rate for illicit drug use was lower compared with the Oslo site, at $1.4 \%$, with THC being the most common $(1.1 \%)$. The rates for the remaining substances in both sites were low.

Cut-off values at each of the two sites were not identical due to differences in analytical methods, with a lower S/N ratio at the Oslo site. We have therefore provided mean concentrations for the substances detected at the Oslo site, which in the majority of substances are well above the analytical cut-off.

\section{Sample characteristics}

Tables 3 and 4 show the unadjusted distribution for psychoactive medicinal drug users and non-users across all covariates measured in Oslo and Moscow, respectively. Medicinal drug use was evenly distributed among genders at both sites. In Oslo, the highest proportion of medicinal drug use was found among patients aged older than 40 years, as well as among those being retired, and/or in the lowest AUDIT-4 ranges. In Moscow, medicinal drug use was more evenly distributed across all age groups, with the highest proportion of use among patients that were non-active in the workforce.

Table 5 depicts logistic regression analysis for various covariates in the Oslo site. Compared with patients aged 18 to 40 years, the likelihood for medicinal drug use was higher among patients aged 41 years and older. There was no significant gender difference among medicinal drug users. The likelihood for polyuse was higher among

Table 5 Logistic regression analysis of demographic characteristics, AUDIT-4 and SCL-5 for medicinal drugs*, illicit drugs and polyuse in Oslo

\begin{tabular}{|c|c|c|c|c|c|c|c|c|c|}
\hline & \multicolumn{3}{|l|}{ Illicit drugs } & \multicolumn{3}{|c|}{ Medicinal drugs } & \multicolumn{3}{|c|}{ Polyuse } \\
\hline & OR & $95 \% \mathrm{Cl}$ & P value & OR & $95 \% \mathrm{Cl}$ & P value & OR & $95 \% \mathrm{Cl}$ & $P$ value \\
\hline \multicolumn{10}{|l|}{ Age (years) } \\
\hline 41 to 60 & 0.40 & 0.23 to 0.67 & $<0.001$ & 1.71 & 1.24 to 2.38 & $<0.05$ & 1.34 & 0.83 to 2.15 & 0.23 \\
\hline 61 to 70 & 0.12 & 0.05 to 0.27 & $<0.001$ & 2.40 & 1.61 to 3.58 & $<0.001$ & 1.51 & 0.87 to 2.64 & 0.15 \\
\hline \multicolumn{10}{|l|}{ Gender } \\
\hline Male & Reference & & & & & & & & \\
\hline Female & 0.37 & 0.24 to 0.58 & $<0.001$ & 0.86 & 0.70 to 1.06 & 0.15 & 0.79 & 0.60 to 1.05 & 0.10 \\
\hline \multicolumn{10}{|l|}{ SCL-5 } \\
\hline$\leq 2$ & Reference & & & & & & & & \\
\hline Divorced & 3.30 & 1.79 to 6.10 & $<0.001$ & 1.30 & 0.98 to 1.74 & 0.07 & 1.75 & 1.21 to 2.53 & $<0.05$ \\
\hline Widowed & 0.74 & 0.09 to 5.92 & 0.77 & 1.47 & 1.01 to 2.12 & 0.04 & 1.49 & 0.90 to 2.45 & 0.12 \\
\hline Single & 1.78 & 1.12 to 2.85 & $<0.05$ & 1.28 & 1.01 to 1.64 & 0.05 & 1.28 & 0.91 to 1.79 & 0.16 \\
\hline \multicolumn{10}{|l|}{ Employment } \\
\hline Active & Reference & & & & & & & & \\
\hline Retired & 2.20 & 0.83 to 5.83 & 0.11 & 2.07 & 1.40 to 3.07 & $<0.001$ & 3.82 & 2.22 to 6.59 & $<0.001$ \\
\hline Non-active & 6.29 & 3.74 to 10.58 & $<0.001$ & 3.82 & 2.80 to 5.21 & $<0.001$ & 7.36 & 4.87 to 11.14 & $<0.001$ \\
\hline \multicolumn{10}{|l|}{ AUDIT-4 } \\
\hline
\end{tabular}

${ }^{*}$ Medicinal drugs defined as benzodiazepines, z-hypnotics or opioids.

AUDIT-4, Alcohol Use Disorder Identification Test-4; SCL-5, Symptom Checklist 5. 
Table 6 Logistic regression analysis of demographic characteristics, AUDIT-4 and SCL-5 for medicinal drugs, ${ }^{*}$ illicit drugs and polyuse in Moscow

\begin{tabular}{|c|c|c|c|c|c|c|c|c|c|}
\hline & \multicolumn{3}{|l|}{ Illicit drugs } & \multicolumn{3}{|c|}{ Medicinal drugs } & \multicolumn{3}{|c|}{ Polyuse } \\
\hline & OR & $95 \% \mathrm{Cl}$ & $P$ value & OR & $95 \% \mathrm{Cl}$ & $P$ value & OR & $95 \% \mathrm{CI}$ & $P$ value \\
\hline \multicolumn{10}{|l|}{ Age (years) } \\
\hline 18 to 40 & Reference & & & & & & & & \\
\hline 41 to 60 & 0.19 & 0.09 to 0.42 & $<0.001$ & 0.62 & 0.43 to 0.88 & 0.01 & 0.29 & 0.12 to 0.70 & $<0.05$ \\
\hline 61 to 70 & 0.07 & 0.05 to 0.83 & $<0.05$ & 0.67 & 0.40 to 1.12 & 0.13 & 0.10 & 0.02 to 0.39 & $<0.05$ \\
\hline $71+$ & 0.00 & 0.00 & 0.99 & 0.81 & 0.47 to 1.40 & 0.44 & 0.12 & 0.03 to 0.50 & $<0.05$ \\
\hline \multicolumn{10}{|l|}{ Gender } \\
\hline Male & Reference & & & & & & & & \\
\hline Female & 0.22 & 0.09 to 0.53 & $<0.001$ & 1.02 & 0.77 to 1.34 & 0.91 & 0.50 & 0.25 to 1.02 & 0.06 \\
\hline \multicolumn{10}{|l|}{ SCL-5 } \\
\hline$\leq 2$ & Reference & & & & & & & & \\
\hline$>2$ & 1.44 & 0.53 to 3.91 & 0.47 & 1.68 & 1.18 to 2.39 & $<0.05$ & 2.09 & 0.94 to 4.63 & 0.07 \\
\hline \multicolumn{10}{|l|}{ Marital status } \\
\hline Married/co-habitant & Reference & & & & & & & & \\
\hline Divorced & 2.14 & 0.90 to 5.08 & 0.09 & 1.39 & 1.00 to 1.95 & 0.05 & 1.49 & 0.66 to 3.34 & 0.34 \\
\hline Widowed & 3.27 & 0.66 to 16.10 & 0.15 & 1.34 & 0.96 to 1.85 & 0.08 & 1.22 & 0.47 to 3.17 & 0.68 \\
\hline Single & 1.65 & 0.78 to 3.46 & 0.19 & 0.95 & 0.63 to 1.44 & 0.81 & 1.19 & 0.50 to 2.84 & 0.70 \\
\hline \multicolumn{10}{|l|}{ Employment } \\
\hline Active & Reference & & & & & & & & \\
\hline Retired & 1.13 & 0.57 to 2.23 & 1.13 & 1.90 & 1.35 to 2.66 & $<0.001$ & 2.21 & 0.96 to 4.90 & 0.05 \\
\hline Non-active & 0.23 & 0.02 to 2.84 & 0.23 & 1.46 & 0.94 to 2.27 & 0.09 & 4.89 & 1.52 to 15.71 & $<0.05$ \\
\hline \multicolumn{10}{|l|}{ AUDIT-4 } \\
\hline 0 to 3 & Reference & & & & & & & & \\
\hline 4 to 6 & 0.86 & 0.31 to 2.40 & 0.87 & 0.73 & 0.42 to 1.26 & 0.26 & 1.04 & 0.35 to 3.13 & 0.94 \\
\hline 7 to 8 & 1.14 & 0.36 to 3.61 & 1.14 & 1.22 & 0.66 to 2.28 & 0.53 & 0.48 & 0.06 to 3.72 & 0.48 \\
\hline 9 to 16 & 0.87 & 0.39 to 1.91 & 0.87 & 2.81 & 2.04 to 3.87 & $<0.001$ & 1.59 & 0.75 to 3.37 & 0.23 \\
\hline
\end{tabular}

*Medicinal drugs defined as benzodiazepines, barbiturates or opioids.

AUDIT-4, Alcohol Use Disorder Identification Test-4; SCL-5, Symptom Checklist 5 .

non-employed patients compared with patients being active in the workforce-this was also observed in regards to illicit substances as well as medicinal drug use. In the Oslo site, female patients were also significantly less likely to use illicit drugs than male patients. Patients aged 18 to 40 years were more likely to use illicit drugs than other age groups. The use of medicinal drugs, illicit drugs, and polyuse was significantly more likely in patients scoring above the cut-off value for SCL-5 (>2).

In the Moscow site (table 6), similar trends for SCL-5 were observed, where patients scoring above the cut-off value were more likely to use medicinal drugs. However, there was no significant difference in the likelihood for polyuse and illicit drug use. Contrary to the Oslo site, the presence of medicinal drugs and polyuse was significantly less likely in patients aged 41 to 60 years. Being retired increased the likelihood for medicinal drug use compared with patients being actively employed-the same association was not statistically significant for patients being non-active in the workforce.

Tables 7 and 8 show the distribution of self-reported use if a sample is positive for either benzodiazepines, opioids, z-hypnotics and illicit drugs, with both benzodiazepines and barbiturates categorised as 'sedatives' in Moscow. If a sample is negative, this is generally mirrored in questionnaires regarding self-reported use. The highest concordance between positive samples and confirmatory self-reported use in Oslo was for z-hypnotics $(75.8 \%)$, followed by opioids $(62.5 \%)$, illicit drugs $(49.4 \%)$ and benzodiazepines $(48.9 \%)$. In Moscow, there was a high concordance between negative samples for opioids and illicit drugs, and self-reported non-use. This percentage was lower for sedatives $(83.2 \%$ for barbiturates and $83.8 \%$ for benzodiazepines). The percentage of sample-positive self-reported use ranged from $7.1 \%$ for opioids to $55.9 \%$ for barbiturates. 
Table 7 Comparison between self-reported intake and laboratory detection of z-hypnotics, opioids, benzodiazepines and illicit drugs at the Oslo site

\begin{tabular}{|c|c|c|c|c|}
\hline Laboratory analysis & No & Yes & Not sure & \\
\hline \multicolumn{5}{|c|}{ Self-reported intake of sleeping medication in last 24 hours } \\
\hline Z-hypnotics & & & & $\mathrm{p}<0.0001$ \\
\hline Negative & $2066(87.2 \%)$ & $291(12.3 \%)$ & $12(0.5 \%)$ & \\
\hline Positive & $40(24.2 \%)$ & $125(75.8 \%)$ & $0(0 \%)$ & \\
\hline \multicolumn{5}{|c|}{ Self-reported intake of painkillers in last 24 hours } \\
\hline Opioids & & & & $\mathrm{p}<0.0001$ \\
\hline Negative & $1875(92.4 \%)$ & $135(6.6 \%)$ & $19(0.9 \%)$ & \\
\hline Positive & $178(36.7 \%)$ & $304(62.5 \%)$ & $4(0.8 \%)$ & \\
\hline \multicolumn{5}{|c|}{ Self-reported intake of sedatives in last 24 hours } \\
\hline Benzodiazepines & & & & $\mathrm{p}<0.0001$ \\
\hline Negative & $1984(96.2 \%)$ & $63(3.1 \%)$ & $15(0.7 \%)$ & \\
\hline Positive & $226(49.6 \%)$ & $223(48.9 \%)$ & $7(1.5 \%)$ & \\
\hline \multicolumn{5}{|c|}{ Self-reported intake of illicit drugs in last 24 hours } \\
\hline Illicit drugs & & & & $\mathrm{p}<0.0001$ \\
\hline Negative & $2344(98.7 \%)$ & $28(1.2 \%)$ & $3(0.1 \%)$ & \\
\hline Positive & $82(50.0 \%)$ & 81 (49.4 \%) & $1(0.6 \%)$ & \\
\hline
\end{tabular}

Figure 3 shows the distribution of psychoactive substances within different AUDIT-4 ranges in Oslo. The highest prevalence of benzodiazepine use was found in the highest AUDIT-4 range (9 to 16 points), with a rate of $31 \%$, compared with $18.5 \%$ for the whole study population. The use of opioids is more prevalent at the lowest and highest AUDIT-4 ranges. The use of THC, stimulants and z-hypnotics is evenly distributed along all AUDIT-4 ranges. In Moscow (figure 4), the highest rate of benzodiazepine use is also found among the highest AUDIT-4 range, while the usage rate for other psychoactive substances is uniformly low in all other AUDIT-4 ranges.

Table 8 Comparison between self-reported intake and laboratory detection of barbiturates, benzodiazepines, opioids and illicit drugs at the Moscow site

\begin{tabular}{|c|c|c|c|c|}
\hline Laboratory analysis & No & Yes & Not sure & \\
\hline & \multicolumn{4}{|c|}{ Self-reported intake of sedatives in last 24 hours } \\
\hline Barbiturates* & & & & $\mathrm{p}<0.0001$ \\
\hline Negative & 2447 (83.2 \%) & 493 (16.8\%) & 1 (0.0 \%) & \\
\hline Positive & $29(42.6 \%)$ & $38(55.9 \%)$ & $1(1.5 \%)$ & \\
\hline \multicolumn{5}{|c|}{ Self-reported intake of sedatives in last 24 hours } \\
\hline Benzodiazepines* & & & & $\mathrm{p}<0.0001$ \\
\hline Negative & $2279(83.8 \%)$ & $438(16.1 \%)$ & $1(0.1 \%)$ & \\
\hline Positive & $197(67.7 \%)$ & $93(32.0 \%)$ & $1(0.3 \%)$ & \\
\hline \multicolumn{5}{|c|}{ Self-reported intake of painkillers in last 24 hours } \\
\hline Opioids & & & & $\mathrm{p}<0.05$ \\
\hline Negative & $2952(99 \%)$ & $27(0.9 \%)$ & $2(0.1 \%)$ & \\
\hline Positive & 26 (92.9 \%) & $2(7.1 \%)$ & $0(0.0 \%)$ & \\
\hline \multicolumn{5}{|c|}{ Self-reported intake of illicit drugs in last 24 hours } \\
\hline Illicit drugs & & & & $\mathrm{p}<0.0001$ \\
\hline Negative & $2959(99.8 \%)$ & $7(0.2 \%)$ & $0(0.0 \%)$ & \\
\hline Positive & 38 (88.4 \%) & 5 (11.6 \%) & 0 (0.0 \%) & \\
\hline
\end{tabular}

*Z-hypnotics are almost completely unavailable in Russia due to various regulatory practices, and there are no drug classes typically marketed as 'sleeping medication'. Barbiturates and benzodiazepines are generally used to treat both anxiety as well as sleep disorders. 


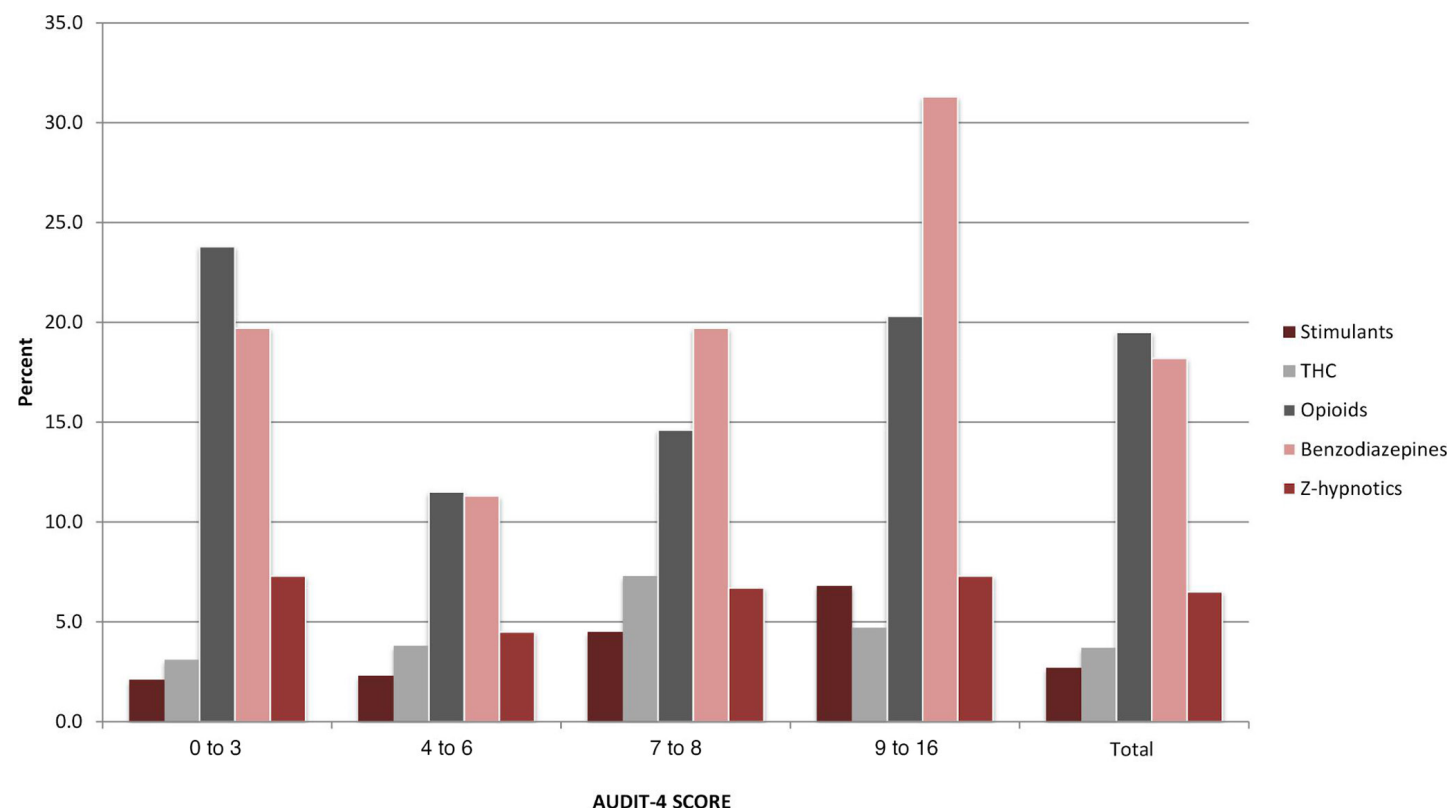

Figure 3 Prevalence of psychoactive substances within AUDIT-4 in Oslo. Percentage of samples positive for stimulants (amphetamines or cocaine), THC, opiates, benzodiazepines and z-hypnotics across AUDIT-4 ranges in Oslo. Results are combined for both men and women. AUDIT-4, Alcohol Use Disorder Identification Test-4; THC, tetrahydrocannabinol.

\section{DISCUSSION}

Our study demonstrates that the use of psychoactive substances among patients admitted to Departments of Internal Medicine is highly prevalent, while simultaneously highlighting differences in sample characteristics between Oslo and Moscow. Based on previous studies, the volume of participants and rate of inclusion provide representative and accurate data. The number of positive sample for psychoactive substances was far higher in Oslo than in Moscow. The use of psychoactive substances in
Oslo was significantly associated with older age, psychological distress and being unemployed. The latter two characteristics are known to be associated with substance use. ${ }^{31}$ There was no significant gender disparity among positive samples-this may be explained by a higher percentage of positive samples among younger males compared with females, and vice versa for older females compared with older males. Previous population-based studies $^{3} 3233$ also show an apparent increase in the use of psychoactive prescription medication in the general

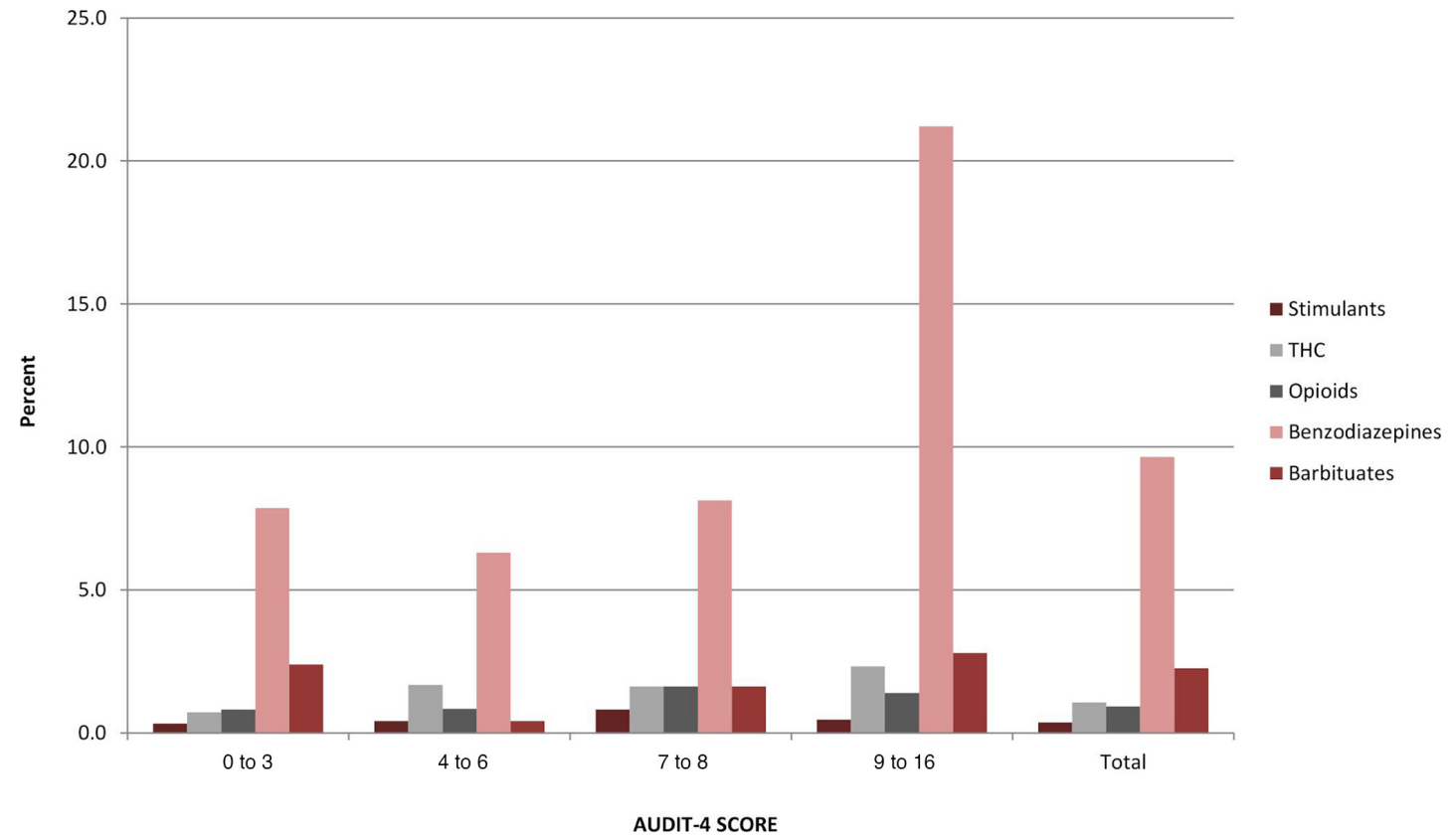

Figure 4 Prevalence of psychoactive substances within AUDIT-4 in Moscow. Percentage of samples positive for stimulants (amphetamines or cocaine), THC, opiates, benzodiazepines and barbiturates across AUDIT-4 ranges in Moscow. Results are combined for both men and women. AUDIT-4, Alcohol Use Disorder Identification Test-4; THC, tetrahydrocannabinol. 
population, particularly among the elderly. However, the drug use statistics were extracted from national prescription databases, and whether or not the patient took the prescribed drug as well as the duration of drug use was not measured. Additionally, substance abuse disorders are more prevalent among non-participants in health surveys. ${ }^{34}$ These factors may underestimate the prevalence of psychoactive substance use-as far as we are aware, this is the first study to demonstrate the frequency of substance use among internal medicine patients.

The high rate of psychoactive substance use among the elderly is a cause for concern. The changes in pharmacodynamics and pharmacokinetics associated with senescence increase complexity when prescribing medications to the elderly. ${ }^{36}$ Inter-individual variability to drugs increases with age, partly explained by reduced physiological reserves during stressors such as inter-current illness or disease. Half-life of elimination is prolonged by changes in body composition, affecting the volume of distribution of lipid-soluble drugs, and reduced renal and hepatic clearance. ${ }^{12}$ These factors alter and increase the sensitivity to psychoactive substances. Elderly patients are particularly sensitive to the effects of benzodiazepines on the central nervous system. Sedation may occur at lower doses than in younger patients. Drowsiness and decreased motor skills, combined with the age-related reduction in functional reserves, increase the risk for immobility and falls. ${ }^{37}$

Physiological reserves in many elderly people may be adequate at normal homeostasis. However, the introduction of a stressor, such as an illness requiring acute hospitalisation, may deplete these reserves, even after the precipitating cause has been corrected ${ }^{38}$ Concurrent use of psychoactive substances and the increased vulnerability to their adverse effects may exacerbate this course. Additionally, conditions which increase in frequency and severity with old age, such as chronic obstructive pulmonary disease, have increased rates of adverse events among users of benzodiazepines and opioids. ${ }^{39}$ Increasing age also increases morbidity and multimorbidity, which in turn is associated with polypharmacy, ${ }^{40}$ with a concurrent increased risk for drug-drug interactions and other adverse effects. ${ }^{41}$ While physicians may be aware of these factors, there is evidence that diversion from clinical guidelines for the prescription of psychoactive medication, in particular benzodiazepines, is widespread. ${ }^{2}$

Regarding self-reported use of benzodiazepines, opioids, z-hypnotics and illicit drugs, there appears to be a high negative predictive value if a patient reports non-use. However, if a sample is positive, under-reporting seems to be prevalent. This differs based on substance category. Patient uncertainty regarding their medication list may contribute ${ }^{42}$ and lead to under-reporting, as well as any potential stigma associated with illicit substance or psychoactive medication use.

The co-occurrence of harmful alcohol use and nonmedical prescription drug use is also well established. ${ }^{43}$
Our study demonstrates primarily increased rates of benzodiazepine use in the upper AUDIT-4 ranges (figures 3 and 4). Whether this reflects co-occurring non-medical prescription drug use or as a reflection of treatment of symptoms related to harmful alcohol use is uncertain.

\section{Clinical implications}

The above considerations, combined with the findings from our study, should prompt an increased awareness regarding the use of psychoactive substances among acutely hospitalised patients. A reduction in inappropriate use or misuse of psychoactive substances may have a positive impact on hospitalisation rates, risk of re-admittance and healthcare costs. Specifically, strengthening and implementing the following practices may contribute to improved patient outcomes:

- Screening for inappropriate or harmful psychoactive substance use

- Critically assessing the indications for psychoactive medicinal drug use and considering discontinuation or tapering if inappropriate prescribing is present

- Assess the degree of increased risk for adverse events in specific conditions when using psychoactive substances, such as chronic obstructive pulmonary disease

- Assess concomitant alcohol use if psychoactive substance use is present

Hospital admissions may serve as opportunities to screen for unapparent harmful use or misuse of psychoactive substances, but this practice is less likely to be performed among elderly patients than among younger individuals. ${ }^{32}$ Health professionals may experience hesitation in screening for unhealthy psychoactive substances use due to the perceived sensitive nature of the subject, ${ }^{44}$ but guidelines for proper communicative techniques exist, which may ameliorate any associated stigma. ${ }^{45}{ }^{46}$ Due to the commonality of substance use disorders among acutely admitted patients, ${ }^{47}$ clinicians may benefit from assessing psychoactive medication use in addition to alcohol and illicit drugs, particularly among the elderly. Similar to screening for alcohol, ${ }^{48}$ validated single-question screening tools exist for illicit drug use and non-medical use of psychoactive medication. ${ }^{49}$ However, these tools were validated in a primary care setting. Older adults may also perceive symptoms of harmful psychoactive substance use as symptoms of ageing, and adverse effects stemming from psychoactive drug use may be similar to manifestations of other conditions. ${ }^{32}$ Single-question screening tools may therefore better serve as an adjunct to the general clinical assessment of every admitted patient.

The use of psychoactive medication is usually mediated by healthcare professionals, which mandates adherence to prescription guidelines. However, based on prescription databases, inappropriate use of benzodiazepines and z-hypnotics is widespread. ${ }^{2}$ Hospital clinicians have the opportunity to prudently assess medication use among 
admitted patients, and are in a position to inform and co-operate with primary care physicians or other health professionals. Any identified instances of harmful or inappropriate use may then be managed by targeted interventions, or discontinuation or drug-tapering. In the event of specific illnesses, it is important to consider whether harmful, inappropriate or even therapeutic use may have precipitated an adverse event. As several illnesses that are more commonly occurring in old age progress, physiological reserves may be depleted. For instance, respiratory depression associated with benzodiazepine use ${ }^{50}$ may cause adverse respiratory events in patients with chronic pulmonary obstructive disease if pulmonary function continues to decrease.

Brief interventions for substance use disorders have shown varying degrees of efficacy in the reduction of harmful alcohol use ${ }^{51-53}$ and illicit drug use, ${ }^{545}$ with some studies showing a reduction in at-risk drinking, while brief interventions have shown no increased efficacy in reducing illicit drug misuse compared with control groups. These studies also did not include elderly patients (above 64 years of age) or the critically ill. Additionally, study participation and the screening process itself may cause a reduction in harmful substance use in both the control group and the groups receiving brief interventions. ${ }^{56}$

While the above recommendations may be valid for Norway and other similar countries in the West, the number of samples positive for psychoactive substances was markedly lower across all age groups in Moscow, at $12 \%$. Plausible causes may be differences in prescription guidelines and legislative practices. Additionally, there were significant differences in the cut-off values used at both sites-in Moscow, the $\mathrm{S} / \mathrm{N}$ ratio cut-off was set at 1000 versus an $\mathrm{S} / \mathrm{N}$ ratio set at 10 in Oslo-this may have underestimated the number of positive samples. However, the usage frequency of psychoactive medications in a Russian ED population may still warrant prudence regarding adherence to prescription guidelines and adverse effects. Their use may also reflect a different selection of illnesses in that particular population-further discussion regarding these elements is beyond the scope of this article.

\section{Limitations}

Previous studies have used both self-reporting and registry-based data to assess substance use among acutely hospitalised patients-a major strength in our study is the addition of blood sample analysis. The analytical methods used have allowed us to identify individual substances, thus increasing the descriptive accuracy in our data. Our inclusion criteria were broad, increasing the likelihood for a representative sample size-this is also strengthened by a high participation rate. The use of two to different hospital sites in two different nations increased our sample size; however, external generalisability to other ED populations is limited to due to differences in medical practice and cultural norms. Differences in analytical cut-off values between Oslo and Moscow also limit the comparability between the two data sets. In order to satisfy necessary ethical considerations, patients unable to give informed consent were excluded. Their cognitive limitations may have been caused by or exacerbated by psychoactive substances or alcohol use-consequently, prevalence data for this patient group remains unavailable. The prevalence of substance use among patients who declined to participate is also a potential bias, as they may have been unwilling to participate due to concerns regarding the disclosure of substance or alcohol use, or may have been incapacitated due to illicit drug use. Finally, substances with a long half-life (such as certain benzodiazepines and z-hypnotics) may have a detection window longer than 24 hours-this may result in a substance-positive sample, but a negative reply regarding self-reported ingestion the past 24 hours.

\section{CONCLUSION}

The use of psychoactive substances among patients acutely admitted to Departments of Internal Medicine is common, and may cause both readily identifiable as well as oblique adverse effects. Health professionals should be aware that the use of benzodiazepines and opiates is highly prevalent, particularly among elderly patients, and should exact prudence when prescribing these drug classes. Implementing screening practices may improve the identification of inappropriate psychoactive substance use.

\section{Author affiliations}

${ }^{1}$ Department of Forensic Sciences, Oslo University Hospital, Oslo, Norway ${ }^{2}$ Department of Internal Medicine, Lovisenberg Diaconal Hospital, Oslo, Norway ${ }^{3}$ Moscow Research and Practical Centre on Addictions, Moscow Department of Health, Moscow, Russia

${ }^{4}$ Russian Medical Academy of Continuous Professional Education, Moscow, Russia ${ }^{5}$ Norwegian Centre for Addiction Research, University of Oslo, Oslo, Norway

${ }^{6}$ Institute of Health and Society, Faculty of Medicine, University of Oslo, Oslo, Norway

${ }^{7}$ Sechenov First Moscow State Medical University, Moscow, Russia

${ }^{8}$ Demikhov Moscow Clinical Hospital, Moscow, Russia

${ }^{9}$ Department of Interdisciplinary Health Sciences, Institute of Health and Society, Faculty of Medicine, University of Oslo, Oslo, Norway

${ }^{10}$ Department of Research, Lovisenberg Diaconal Hospital, Oslo, Norway

Contributors DG drafted the manuscript. BJ, SK and AAN did the initial data analysis. TB performed supplementary data analysis. BJ, SK, WV, DG, AL, GN and STB organised or contributed to the Oslo data collection. EB, EK, AN, ET, AK, AP, SP and ED organised or contributed to the Moscow data collection. All authors were responsible for study design, interpretation of the results, as well as final revision and approval of the manuscript.

Funding The study was supported by the Norwegian Ministry of Health's Funding for Norwegian-Russian Collaboration in Health and Social issues grant B-1408.

Disclaimer The Norwegian Ministry of Health had no role in the design of the study, in the collection, analysis or interpretation of the data, nor in writing the manuscript or in the decision to submit the article for publication.

Competing interests None declared.

Patient and public involvement Patients and/or the public were not involved in the design, or conduct, or reporting, or dissemination plans of this research.

Patient consent for publication Not required. 
Ethics approval This study was approved by the Regional Ethics Committee for South Eastern Norway (2015/2404), and by the Moscow Local Ethical Committee of Moscow Research and Practical Center on Addiction.

Provenance and peer review Not commissioned; externally peer-reviewed. Data availability statement No data are available due to institutional policies. Open access This is an open access article distributed in accordance with the Creative Commons Attribution Non Commercial (CC BY-NC 4.0) license, which permits others to distribute, remix, adapt, build upon this work non-commercially, and license their derivative works on different terms, provided the original work is properly cited, appropriate credit is given, any changes made indicated, and the use is non-commercial. See: http://creativecommons.org/licenses/by-nc/4.0/.

ORCID iD

Danil Gamboa http://orcid.org/0000-0002-8064-779X

\section{REFERENCES}

1 llomäki J, Paljärvi T, Korhonen MJ, et al. Prevalence of concomitant use of alcohol and sedative-hypnotic drugs in middle and older aged persons: a systematic review. Ann Pharmacother 2013;47:257-68.

2 Neutel Cl, Skurtveit S, Berg C. What is the point of guidelines? Benzodiazepine and z-hypnotic use by an elderly population. Sleep Med 2012;13:893-7.

3 Carrasco-Garrido P, López de Andrés A, Hernández Barrera V, et al. National trends (2003-2009) and factors related to psychotropic medication use in community-dwelling elderly population. Int Psychogeriatr 2013;25:328-38.

4 Riggs P. Non-medical use and abuse of commonly prescribed medications. Curr Med Res Opin 2008;24:869-77.

5 Egerton-Warburton D, Gosbell A, Moore K, et al. Alcohol-related harm in emergency departments: a prospective, multi-centre study. Addiction 2018;113:623-32.

6 McLay SV, MacDonald E, Fatovich DM, et al. Alcohol-related presentations to the Royal Perth hospital emergency department: a prospective study. Emerg Med Australas 2017;29:531-8.

7 Vederhus J-K, Rysstad O, Gallefoss F, et al. Assessing alcohol use and smoking among patients admitted to the medical ward. Tidsskr Nor Laegeforen 2015;135:1251-5.

8 Substance Abuse and Mental Health Services Administration (SAMHSA). Highlights of the 2010 drug abuse warning network (dawn) findings on drug-related emergency department visits, 2012. Available: https://www.samhsa.gov/data/sites/default/files/ DAWN096/DAWN096/SR096EDHighlights2010.htm

9 Cherpitel CJ, Ye Y, Stockwell T, et al. Recall bias across 7 days in self-reported alcohol consumption prior to injury among emergency department patients. Drug Alcohol Rev 2018;37:382-8.

10 Bogstrand ST, Normann PT, Rossow I, et al. Prevalence of alcohol and other substances of abuse among injured patients in a Norwegian emergency department. Drug Alcohol Depend 2011;117:132-8

11 Statistics Norway. Patient statistics, 2013. Available: https://www. ssb.no/en/helse/statistikker/pasient/aar/2014-04-09

12 Mangoni AA, Jackson SHD. Age-related changes in pharmacokinetics and pharmacodynamics: basic principles and practical applications. Br J Clin Pharmacol 2004;57:6-14

13 Moore AA, Whiteman EJ, Ward KT. Risks of combined alcohol/ medication use in older adults. Am J Geriatr Pharmacother 2007;5:64-74.

14 Oslin DW. Alcohol use in late life: disability and comorbidity. J Geriatr Psychiatry Neurol 2000;13:134-40.

15 Payne RA, Avery AJ. Polypharmacy: one of the greatest prescribing challenges in general practice. Br J Gen Pract 2011;61:83-4.

16 Beekman AT, Bremmer MA, Deeg DJ, et al. Anxiety disorders in later life: a report from the longitudinal aging study Amsterdam. Int $J$ Geriatr Psychiatry 1998;13:717-26.

17 Statistics Norway. Deaths, 2016. Available: https://www.ssb.no/en/ befolkning/statistikker/dode/aar/2017-03-09

18 The World Bank. Life Expectancy at birth, total - Russian Federation. Available: https://data.worldbank.org/indicator/SP.DYN.LE00.IN? end=2017\&locations=RU\&start=2009

19 Statistics Norway. Life expectancy in Oslo. Available: https://www. ssb.no/befolkning/artikler-og-publikasjoner/fortsatt-store-forskjelleri-levealder-i-oslo

20 Kristoffersen L, Langødegård M, Gaare KI, et al. Determination of 12 commonly found compounds in DUID cases in whole blood using fully automated supported liquid extraction and UHPLC-MS/MS. J Chromatogr B Analyt Technol Biomed Life Sci 2018;1093-1094:8-23.
21 Jones AW, Holmgren A, Kugelberg FC. Driving under the influence of opiates: concentration relationships between morphine, codeine, 6 -acetyl morphine, and ethyl morphine in blood. J Anal Toxicol 2008;32:265-72.

22 Jones AW, Holmgren A. Concentration ratios of methamphetamine to amphetamine in blood can help to distinguish use of methamphetamine from various mixtures of the two stimulants. $J$ Anal Toxicol 2012;36:634-7.

23 Strand BH, Dalgard OS, Tambs K, et al. Measuring the mental health status of the Norwegian population: a comparison of the instruments SCL-25, SCL-10, SCL-5 and MHI-5 (SF-36). Nord J Psychiatry 2003;57:113-8

24 Kabashi S, Vindenes V, Bryun EA, et al. Harmful alcohol use among acutely ill hospitalized medical patients in Oslo and Moscow: a cross-sectional study. Drug Alcohol Depend 2019;204:107588.

25 Gual A, Segura L, Contel M, et al. Audit-3 and audit-4: effectiveness of two short forms of the alcohol use disorders identification test. Alcohol Alcohol 2002;37:591-6.

26 Cook S, De Stavola B, Saburova L, et al. Socio-demographic predictors of dimensions of the AUDIT score in a population sample of working-age men in Izhevsk, Russia. Alcohol Alcohol 2011;46:702-8.

27 Saunders JB, Aasland OG, Babor TF, et al. Development of the Alcohol Use Disorders Identification Test (AUDIT): WHO Collaborative Project on Early Detection of Persons with Harmful Alcohol Consumption--II. Addiction 1993;88:791-804.

28 Hoffmann C, McFarland BH, Kinzie JD, et al. Psychological distress among recent Russian immigrants in the United States. Int J Soc Psychiatry 2006;52:29-40.

29 World Health Organization. Phenazepam. Available: www.who.int/ medicines/access/./5.8_Phenazepam_PreRev.pdf

30 Madras BK. The growing problem of new psychoactive substances (NPS). Curr Top Behav Neurosci 2017;32:1-18.

31 Lee KH, Jun JS, Kim YJ, et al. Mental health, substance abuse, and suicide among homeless adults. J Evid Inf Soc Work 2017; 14:229-42.

32 Kuerbis A, Sacco P, Blazer DG, et al. Substance abuse among older adults. Clin Geriatr Med 2014;30:629-54.

33 Tevik K, Selbæk G, Engedal K, et al. Use of alcohol and drugs with addiction potential among older women and men in a populationbased study. The Nord-Trøndelag health study 2006-2008 (HUNT3). PLoS One 2017;12:e0184428.

34 Knudsen AK, Hotopf M, Skogen JC, et al. The health status of nonparticipants in a population-based health study: the Hordaland health study. Am J Epidemiol 2010;172:1306-14.

35 Torvik FA, Rognmo K, Tambs K. Alcohol use and mental distress as predictors of non-response in a general population health survey: the HUNT study. Soc Psychiatry Psychiatr Epidemiol 2012;47:805-16.

36 Spinewine A, Schmader KE, Barber N, et al. Appropriate prescribing in elderly people: how well can it be measured and optimised? Lancet 2007;370:173-84.

37 Kruse WH. Problems and pitfalls in the use of benzodiazepines in the elderly. Drug Saf 1990;5:328-44.

38 Creditor MC. Hazards of hospitalization of the elderly. Ann Intern Med 1993;118:219-23.

39 Baillargeon J, Singh G, Kuo Y-F, et al. Association of opioid and benzodiazepine use with adverse respiratory events in older adults with chronic obstructive pulmonary disease. Ann Am Thorac Soc 2019;16:1245-51.

40 Moen J, Antonov K, Larsson CA, et al. Factors associated with multiple medication use in different age groups. Ann Pharmacother 2009;43:1978-85.

41 Milton JC, Jackson SHD. Inappropriate polypharmacy: reducing the burden of multiple medication. Clin Med 2007;7:514-7.

42 Tam VC, Knowles SR, Cornish PL, et al. Frequency, type and clinical importance of medication history errors at admission to hospital: a systematic review. CMAJ 2005;173:510-5

43 Blanco C, Rafful C, Wall MM, et al. The latent structure and predictors of non-medical prescription drug use and prescription drug use disorders: a national study. Drug Alcohol Depend 2013;133:473-9.

44 Tourangeau R, Yan T. Sensitive questions in surveys. Psychol Bull 2007;133:859-83.

45 Botticelli MP, Koh HK. Changing the language of addiction. JAMA 2016;316:1361-2.

46 Kelly JF, Wakeman SE, Saitz R. Stop talking 'dirty': clinicians, language, and quality of care for the leading cause of preventable death in the United States. Am J Med 2015;128:8-9.

47 Hankin A, Daugherty M, Bethea A, et al. The emergency department as a prevention site: a demographic analysis of substance use among ED patients. Drug Alcohol Depend 2013;130:230-3. 
48 Smith PC, Schmidt SM, Allensworth-Davies D, et al. Primary care validation of a single-question alcohol screening test. J Gen Intern Med 2009;24:783-8.

49 Smith PC, Schmidt SM, Allensworth-Davies D, et al. A singlequestion screening test for drug use in primary care. Arch Intern Med 2010;170:1155-60.

50 Vozoris NT, Fischer HD, Wang X, et al. Benzodiazepine use among older adults with chronic obstructive pulmonary disease: a population-based cohort study. Drugs Aging 2013;30:183-92.

51 Landy MSH, Davey CJ, Quintero D, et al. A systematic review on the effectiveness of brief interventions for alcohol misuse among adults in emergency departments. J Subst Abuse Treat 2016;61:1-12.

52 Barata IA, Shandro JR, Montgomery M, et al. Effectiveness of SBIRT for alcohol use disorders in the emergency department: a systematic review. West J Emerg Med 2017;18:1143-52.
53 McGinnes RA, Hutton JE, Weiland TJ, et al. Review article: effectiveness of ultra-brief interventions in the emergency department to reduce alcohol consumption: a systematic review. Emerg Med Australas 2016;28:629-40.

54 Merchant RC, Baird JR, Liu T. Short-Term efficacy of a brief intervention to reduce drug misuse and increase drug treatment utilization among adult emergency department patients. Acad Emerg Med 2015;22:1172-80.

55 Guan W, Liu T, Baird JR, et al. Evaluation of a brief intervention to reduce the negative consequences of drug misuse among adult emergency department patients. Drug Alcohol Depend 2015;157:44-53.

56 Bernstein JA, Bernstein E, Heeren TC. Mechanisms of change in control group drinking in clinical trials of brief alcohol intervention: implications for bias toward the null. Drug Alcohol Rev 2010;29:498-507. 